\title{
Conditions for Survival: changing risk and the performance of hedge fund managers and CTAs
}

\author{
Stephen J. Brown, NYU Stern School of Business \\ William N. Goetzmann, Yale School of Management \\ James Park, PARADIGM Capital Management, Inc.
}

June 30, 1999

\begin{abstract}
Investors in hedge funds and commodity trading advisors [CTA] are naturally concerned with risk as well as return. In this paper, we investigate whether hedge fund and CTA return variance depends upon whether the manager is doing well or poorly. Our results are consistent with the Brown, Harlow and Starks (1996) findings for mutual fund managers. We find that good performers in the first half of the year reduce the volatility of their portfolios, and poor performers increase volatility. These "variance strategies" depend upon the fund's ranking relative to other funds. Interestingly enough, despite theoretical predictions, changes in risk are not conditional upon distance from the high water mark threshold, i.e. a ratcheting absolute manager benchmark. This result may be explained by the relative importance of fund termination. We analyze factors contributing to fund disappearance. Survival depends on both absolute and relative performance. Excess volatility can also lead to termination. Finally, other things equal, the younger a fund, the more likely it is to fail. Therefore our results strongly confirm an hypothesis of Fung and Hsieh (1997b) that reputation costs have a mitigating effect on the gambling incentives implied by the manager contract. Particularly for young funds, a volatility strategy that increases the value of a performance fee option may lead to the premature death of that option through termination of the fund. The finding that hedge fund and CTA volatility is conditional upon past performance has implications for investors, lenders and regulators.
\end{abstract}

Acknowledgements: The authors thank TASS for providing their data for analysis. We thank David Hsieh for his encouragement with the project, Jennifer Carpenter, Ian Domowitz and Steven Heston for their helpful comments, and both Markus Karr and Jeremy Staum for able assistance programming and in preparation of the data. In addition, we acknowledge the contributions of participants at presentations at a December 1997 CBOT conference, the 1999 American Finance Association meetings and at Pennsylvania State University. All errors are the sole responsibility of the authors. 


\section{Introduction}

Hedge funds and commodity trading advisors [CTAs] are curiosities in the investment management industry. Unlike mutual funds and most pension fund managers, they have contracts that specify a dramatically asymmetric reward. Hedge fund managers and commodity trading advisors are both compensated with contracts that pay a fixed percentage of assets and a fraction of returns above a benchmark of the treasury bill rate or zero. In addition, most of these contracts contain a "high water mark" provision that requires the manager to make up past deficits before earning the incentive portion of the fee. Essentially, this feature resets the exercise price of the call option incentive by the amount of unmet prior year targets. What effect does this asymmetric contract have upon their incentives to invest effort and take risks? Goetzmann, Ingersoll and Ross (1997), Grinblatt and Titman (1989) and Carpenter (1997) all show analytically that the value of the manager's contract is increasing in portfolio variance due to the call-like feature of the incentive contract. In fact, Carpenter (1997) identifies a strategy where variance depends upon the distance of the net asset value of the portfolio from the high water mark - out-of-the-money managers have a strong incentive to increase variance, while in the money managers lower risk. On the other hand, Fung and Hsieh (1997b) argue that the "high water mark" reset provision actually serves to mitigate the gambling incentives of the call option manager contract, while conceding that deep out of the money managers have an "all or nothing" incentive to gamble. Starks (1987) explores the tradeoffs between symmetric and asymmetric manager contracts and finds that this incentive to increase risk makes the asymmetric reward less attractive than a symmetric reward as an investment management contract. Her theory, as with Carpenter (1997) has testable implications about the variance strategies of money managers with 
asymmetric contracts.

Brown Harlow and Starks (1995) [BHS] present fascinating evidence on mutual fund variance strategies, however they can only examine the behavior of managers compensated by fixed or at best symmetric compensation plans: mutual funds are precluded by law from asymmetric rewards. Hedge fund and CTA data allow us to do something they could not namely examine the variance strategies of managers compensated asymmetrically. We use the BHS methodology to examine how changes in fund variance depend upon performance in the first half of the year. Our results are puzzling — despite major differences in the form of manager compensation, we find little difference between the behavior of hedge fund/CTA managers and mutual fund managers. We identify a significant reduction in variance conditional upon having performed well. Given the compensation arrangements, we would expect that poor performers who survive increase volatility to meet their high water mark. However, this does not appear to be the case in our database of hedge fund/CTA managers.

In order to see how the variance strategy interacts with the high water mark threshold, we explore whether manager strategies are conditional upon absolute versus relative performance cutoffs. While the high-water-mark contract is designed to induce behavior conditional upon absolute performance, in fact we find evidence that the variance strategy depends on relative performance. These variance strategies do not depend at all on absolute performance despite the popular perception that hedge fund managers are market neutral and care only about absolute performance. However, this result is consistent with the theory and empirical results in Massa (1997) who finds that relative ranking will tend to dominate as the basis for manager behavior. Our findings have implications for investors, lenders and regulators. If hedge fund and 
CTA risk depends upon relative performance, then investors and lenders can adjust their exposure to such risk accordingly. Our negative findings regarding risk-taking conditional upon poor absolute performance should be valuable to regulators concerned with preparing for worstcase scenarios.

Why don't hedge fund managers and CTAs behave like theory says they should? Some kind of severe penalty, such as termination, would seem necessary to justify our evidence on the variance-response function of hedge fund managers and CTAs to interim performance. Although there is little in the high water mark contract to explicitly penalize poorly performing managers there are great implicit costs to taking risks that might lead to termination. In Brown, Goetzmann and Ibbotson (1997) (BGI) we find that about 20\% of off-shore hedge funds disappear each year. Fung and Hsieh (1997b) report that 20\% of their CTA sample disappears each year. Updating and extending their database does not change this conclusion. In our sample of hedge fund managers, $15 \%$ disappear each year. Consistent with the results reported in BGI, the half life of a fund in our sample is less than $2^{1 / 2}$ years. Fung and Hsieh identify the threat of withdrawals as a "reputation cost" that may in fact discipline the risk-taking of under-performers. We find that this reputation cost hypothesis is strongly supported in our data.

The question of survival conditioning is potentially important to cross-sectional performance studies. We examine the factors associated with funds "exiting" our database. Negative returns over one year and two year horizons do increase the likelihood of fund termination. However, even controlling for this, relative returns and volatility also play a significant role. The younger the fund, other things equal, the more likely it is to be terminated. 
Our survival analysis lends strong support to the conjecture that CTAs and hedge fund managers are seriously concerned with closure, as opposed to maximizing the option-like feature of their contract.

Brown, Goetzmann, Ibbotson and Ross (1992) point out that survivorship can induce spurious persistence in relative fund returns. Hendricks, Patel and Zeckhauser (1997) discover that survival induces a "J-shape" in performance and variance conditional upon past returns, while Carhart (1997) and Carpenter and Lynch (1999) show how multi-period survival conditioning induces contrasting patterns in persistence tests. Our statistical results give strong support to the notion that this database evidences significant multi-period survival conditioning of the type analysed by Carpenter and Lynch (1999). How this attrition affects various other statistical tests about hedge fund and CTA return is a question to be addressed by researchers in the field.

This paper is structured as follows. The next section discusses the data. Section 3 reports the results of our empirical analysis, section 4 considers the causes of fund attrition in detail and section 5 concludes.

\section{Available fund data}

TASS is a New York-based advisory and information service that maintains a large database of CTA and hedge fund managers that we used in this analysis. This TASS data is used in recent research by Fung and Hsieh (1997a\&b). A competitor to TASS, Managed Account Reports (MAR) has data on both manager populations as well, and this is the data used by 
Ackerman, McEnally and Ravenscraft (1999) and Park (1995). Neither of these two sources is a "follow-forward" database of the kind used in BGI. Consequently we could not verify the extent to which defunct funds have been dropped from the sample until very recently. TASS has recognized the importance of maintaining defunct funds in their data, and since 1994 they have kept records of hedge funds that cease to operate. Fung and Hsieh (1997b) find evidence that the survival bias in the TASS CTA returns is more than $3 \%$ per year. Because of the limited coverage of the database before 1988, we use TASS data for the period 1989-98 in our study. We have augmented this database by hand collecting missing data, and by using information provided by Daniel B. Stark \& Co., Inc. for CTA data not covered by TASS. Table 1 contains a count of the funds in this augmented database.

Survival is not the only potential conditioning in the data. Park's (1995) analysis of the MAR data suggests that funds are typically brought into the database with a history. This conditioning has two separate implications. First, a fund might be brought in because the manager has chosen to report a good track record -- i.e., self-selection bias. Second, a survival bias is imparted because having a two-year or more track record implies that the fund survived for two years, while others with similar characteristics failed. Ackermann, McEnally and Ravenscraft(1999) have an extensive analysis of these different sources of bias in a similar hedge fund sample. Table I reports the time-series counts of CTAs and hedge funds. Notice that survival is an important issue for TASS' CTAs — roughly 20\% disappear per year since 1990. The 20\% attrition rate for CTAs is consistent with the numbers in BGI for offshore hedge funds. The attrition rates for the TASS hedge funds are suspiciously lower — less than 15\% per year since 1994. However, the half life of the TASS hedge funds is exactly 30 months (Figure 1), 
which corresponds to the offshore hedge fund results reported by BGI. CTA funds have a shorter half life of only two years.

Recent evidence suggests that both single-period and multi-period conditioning implies that analysis of surviving fund returns can lead to false inferences (Carhart (1997), Carpenter and Lynch (1997) and Hendricks, Patel and Zeckhuaser (1997)). Evidence suggests that multiperiod conditioning is indeed a feature of this industry. Therefore it seems likely that the statistical analysis of both of these databases is likely to be biased. Fortunately, the direction of at least some of these biases are well understood and will be discussed further in Section IV.

\section{Survival Strategies}

\section{III.1 Sorts by Deciles}

Following BHS, we test whether fund performance in one period explains the change in variance of fund returns in the following period. Figures 2 and 3 show the simplest form of this test for CTAs and hedge funds. For each year in the sample, we compute performance deciles based on January through June total return. We then compute monthly returns in excess of style benchmarks ${ }^{1}$ and calculate the variance of excess returns for the period January-June and JulyDecember. The ratio of these two numbers is then a measure of the extent to which fund managers increase volatility in the course of the year. The figures plot the median variance ratio

${ }^{1}$ Eight style benchmarks were computed for this data using the GSC approach described in Brown and Goetzmann (1997), a returns based procedure which like the technique described by Fung and Hsieh (1997), allows styles to be characterized by time-varying factor exposure. Ackerman McEnally and Ravenscraft (1999) define style benchmarks using self-described style characterizations provided to HFR. To the extent that styles share common risk characteristics, this provides some extent of risk adjustment to returns. An earlier version of this paper reports results using the volatility of raw returns, with very similar results. 
by performance decile. They show clear evidence that funds that do exceptionally well in the first half of the year reduce variance. This is true for both hedge funds (Figure 2) and CTAs (Figure 3). In both cases the reduction in volatility is most significant in the highest decile of performance. In addition, hedge funds and CTAs that perform worse than the median manager increase variance.

A simple explanation for this pattern of variance changes is that funds adopt a passive leverage policy. Most of the funds in the sample use a substantial amount of leverage. Passive leverage is one possible explanation for the very high leverage ratios reported for Long-Term Capital Management in September 1998. As the asset value of the fund fell, borrowing was constant. The further the fund fell in value, the higher was its leverage and consequent volatility. As the value of the fund rose again, leverage fell and so too did volatility.

To test this theory, we divided the sample up into those who lost money, and those who gained during the first six months. The average leverage for the first group will have risen and the average leverage for the second group will have fallen over the sample period. The passive leverage hypothesis would predict that the first group will experience a rise in volatility, with the greatest rise among those funds whose loss in the second period was greater than the loss in the first period. The same hypothesis would predict that the funds that made money in the first six months will experience a fall in volatility. The largest decrease in volatility will occur among those funds whose return July through December exceeds the positive return in the first half of the year. Neither implication is supported in the data ${ }^{2}$.

${ }^{2}$ Taking the funds that lost money in the first six months, those that gained more in the second six months than they had lost in the first six months should have experienced a decrease or no change in volatility as the average leverage did not increase. However, the median volatility 
While poor performers do increase variance, it is somewhat surprising to find that the greatest increase in volatility occurs among the median performers, rather than among the worst performers. The increase in volatility among the poor performers is only marginally significant. Given that the manager's incentive is essentially a call option with exercise price determined by the high water mark provision, one would expect a rational manager to increase the value of this out-of-the-money option by increasing variance ${ }^{3}$. Indeed, this is the classic moral hazard problem induced by asymmetric incentives. Given that $20 \%$ of CTA managers disappear each year since 1990, any fund in the lowest decile may have a reasonably high probability of disappearance. Any manager who judges his or her likelihood of disappearance at mid year as a virtual certainty has a powerful incentive to "double down" by taking much higher risks. Clearly, another factor must be at work that persuades poorly performing managers to limit any increase in volatility.

One conjecture is that conditioning upon survival over several periods will eliminate

ratio was actually 1.1561 , contrary to the passive leverage hypothesis. Other funds ought to have experienced a rise in volatility, with the greatest increase occurring for those funds that lost as much in the second period as they had lost in the first period. However, while it is true that the extreme losers did in fact increase volatility, with a median variance ratio of 1.1739 , the other funds actually decreased volatility, with a variance ratio of 0.9331 , contrary to the passive leverage hypothesis. A similar pattern holds for funds that made money in the first six months. Those who made more money by the end of the year than they had made in the first six months and for which, by the passive leverage hypothesis, we would expect to have a substantial reduction in volatility actually increased volatility with a variance ratio of 1.1003 . Funds that lost more than they had won also had an increased volatility with a variance ratio of 1.2578 , while all other winning funds had a volatility ratio of .9731 . In each case, the difference from one is significant at the $5 \%$ level.

${ }^{3}$ However, note that this call option argument may actually be consistent with the median manager having a substantial incentive to increase volatility, as the vega is greatest for at the money options. We thank Steve Heston for this observation. 
funds with really bad returns from the sample. Fung and Hsieh (1997b) examine a closely related conjecture about extreme poor performers, which they term an "end-game" strategy. They offer another hypothesis that may explain why poor performers do not "double down." They look at firms that are likely to go out of business. Those that are part of a multi-fund firm, they assert, will be less likely to take big risks when they are down, and more likely to be shut down before doing really poorly. This is because a poor performer makes the whole firm look bad. In fact, they find that CTA funds in multi-manager firms do relatively better, and take less systematic risk -- both consistent with the hypothesis that there are reputational externalities that may prevent big gambles. Our results appear to provide strong support for this hypothesis.

\section{2 Contingency Table Tests}

Tables 2, 3 and 4 tests the significance of the strategic use of variance by the funds in our sample, broken down by CTAs and hedge funds. These results are exactly conformable with similar results reported by BHS for a six-month comparison period. This period represents half of the normal annual reporting period for hedge funds and CTAs. If we define high return funds as funds whose six month return is in excess of that of the median fund, we find on a year by year basis that high return funds increase variance while low return funds decrease variance. This is true nine years out of ten for the whole sample, eight years out of ten for CTAs and five out of ten for hedge fund. The pattern is statistically significant for all years taken together. The reversals of pattern are small in number and in any event are not statistically significant. The magnitude of these numbers matches the numbers reported on a similar basis by BHS.

These results seem to suggest that poor performers do indeed increase the volatility of 
their funds as a strategic response to the nature of their performance incentive contract. Taken at face value, it would appear that the managers are responding to the fact that their options are out of the money by increasing variance. However, this hypothesis is not correct. The second panel of each of the tables examines the strategic response to whether the performance fee options are in or out of the money ${ }^{4}$. Here we find a very different picture. Not only do we fail to find that losers increase volatility and winners decrease volatility. Sometimes, losers actually decrease volatility, and winners increase volatility. In any event, the strategic volatility pattern is significant in only one year for each of the fund groupings, and is insignificant over all years. Evidently, performance relative to other funds is important, while performance relative to the high water mark is not.

Is this pattern induced by survival? Simulations approximating these strategic variance tests are reported in Brown, Goetzmann, Ibbotson and Ross (1997). We show that a 10\% performance cut on the first period, corresponding to the elimination of the worst decile of performers would induce a "J" shape response of variance to returns. To the extent that the strategic variance effect is a reduction of variance by winners, the simulations in the BGIR 97

${ }^{4}$ Note however, that while a return less than zero implies that the managers' option is out of the money, it does not follow that a positive return implies that the option is in the money. Some managers are evaluated relative to a Tbill return benchmark, and of course managers whose high water mark provision increased on account of a poor previous period return require a substantial positive return before their incentive contract is in the money. It is difficult to model the in the moneyness of the option due to these differences, and the fact that not all high water marks are adjusted on an annual frequency. However, the results in the tables were repeated assuming a zero benchmark and annual benchmark reset. We find that $50.56 \%$ of all funds 1990-1998 whose option was out of the money at half year, increased volatility relative to the median manager, while the corresponding number for hedge funds is $51.14 \%$ and for CTAs is $50.42 \%$. These numbers are insignificantly different economically and statistically from $50 \%$. 
article would bias the test towards type II error. In addition, survival arguments would suggest that winners would ex post display an increase in variance ${ }^{5}$. Thus, we do not believe the results are due to conditioning upon survival over the year-long period.

\section{Attrition and Relative Performance}

While the high-water-mark contract is designed to induce behavior conditional upon absolute performance, the results in Figures 2 and 3, and Tables 2, 3 and 4 provide evidence that managers pay more attention to their performance relative to the rest of the industry. This is despite the popular perception that hedge fund managers are market neutral and care only about absolute performance. These results are comprehensible however, if we understand that the incentive fee option expires on termination of the fund. If poor relative performance and increased volatility increase the probability of termination, then indeed managers ought to care about these issues. To examine how reasonable this conjecture is, we examine the extent to which these factors do indeed play a role in fund termination.

Table 5 reports the results from two kinds of analysis that support the contention that both relative and absolute performance over multiple periods play a role in fund termination. Volatility and seasoning are also important factors. For every quarter end from December 1989 (December 1993 for hedge funds) we record the one quarter, one year and two year performance characteristics, volatility and seasoning. We then record whether the fund survives the following

${ }^{5}$ Suppose $\alpha_{1}$ and $\alpha_{2}$ are the first and second period performance levels, independent and identically distributed and suppose further that survival requires $\alpha_{1}+\alpha_{2}>c$. Ex post survival conditioning implies that second period variance is increasing in first period performance. Note that $\operatorname{Var}\left[\alpha_{2} \mid \alpha_{1}=a \& \alpha_{1}+\alpha_{2}>c\right]=\operatorname{Var}\left[\alpha_{2} \mid \alpha_{2}>c-a\right]$ is an increasing function of first period performance $a$. We thank Jennifer Carpenter for this observation. 
quarter and perform a standard Probit analysis of fund termination. The results are reported in the first panel of Table 5 .

For CTA funds, poor absolute performance over both a one year and a two year holding period basis increase significantly the probability of fund termination. This is consistent with a view that fund managers voluntarily terminate funds where there is no reasonable possibility of meeting an increasing high water mark provision in the incentive contract. However, short term relative performance and volatility also play a role. This suggests that not increasing volatility may be quite rational for managers already at risk because of poor performance. The increase in volatility may increase the chance of the incentive contract ending up in the money, but may of itself increase the probability of termination and poor short term returns that would also contribute to termination. In addition, it does appear that seasoning plays a role. The longer the fund has been in existence, the more likely it is to survive.

It is interesting to compare CTA results and hedge fund results. While most of the results are similar across the two fund groups, they differ in two important respects. While short term poor performance is less important for hedge funds, hedge funds are more likely to be terminated if they have poor relative performance measured on an annual basis. The Investment Company Act of 1940 imposes important restrictions on the distribution of information about hedge funds, whereas CFTC regulation implies that CTA clients have access to reliable and timely information to evaluate relative performance. This is at least a partial explanation for the relative importance of short term performance information for CTAs. Another important difference is that after controlling for relative performance, seasoning and volatility, hedge funds 
are increasingly more likely to be terminated. While this may be a Long-Term Capital Management spillover effect, it appears to have been evident before the well-publicized problems of that particular hedge fund.

The role of seasoning bears a closer examination. In a recent paper, Lunde, Timmermann and Blake (1999) argue persuasively that this kind of Probit analysis is too restrictive. It requires not only strong distributional assumptions, but also strong parametric assumptions about the role of seasoning in the survival of funds. They argue for a semi parametric Cox hazard rate regression approach. Applying this to the data yields almost precisely the same answers as the Probit analysis. It confirms that our results are robust to the way we have modeled survival.

\section{Conclusion}

Although we find strong evidence of the BHS strategic variance effect on a very different sector of the money management industry, closer examination reveals a conundrum. Managers whose performance is relatively poor increase the volatility of their funds, whereas managers whose performance is particularly favorable decrease volatility. This is consistent with adverse incentives created by the existence of performance-based fee arrangements. A corollary of this theory is that managers whose performance contract is out of the money should increase volatility the most. The data simply does not support this further implication. Managers whose return is negative do not substantially increase volatility. In some years of our sample they even decrease the volatility of their fund's return. Thus, while the data fit with certain conjectures derived from theory about investment manager compensation, they appear to contradict others.

Despite the feeling that most hedge funds are market neutral, and therefore only care 
about absolute returns, we find that relative returns and volatility play a role in determining which funds survive and which funds fail. In addition, the longer a fund is in business, the less likely it is to fail. Since the managers performance fee contract dies with the fund, it is perfectly reasonable that they should care about relative performance and avoid excess volatility. This is particularly true for young funds. Such funds are more likely to fail other things equal. CTA funds in particular are most sensitive to poor relative performance on the short term. This is possibly explained by greater access to reliable and timely information with which to evaluate relative performance.

Our analysis of this database reveals some interesting things about fund attrition and conditions under which data in the CTA and hedge fund industry is collected. Survival of hedge fund data does indeed appear to evidence the kind of multi-period conditioning analyzed by Carpenter and Lynch (1999). Analysts concerned with single-period and multi-period conditioning biases will have both to worry about. While this has relatively little influence on the analysis of styles, as in Hsieh and Fung (1997) it can be misleading to studies of performance persistence and risk-adjusted returns to the industry as a whole. 


\section{References}

Ackerman, Carl, Richard McEnally and David Ravenscraft, 1999, "The performance of hedge funds: risk, return and incentives," Journal of Finance 54(3) 833-874

Brown, Keith, Van Harlow and Laura Starks, 1996, "Of tournaments and temptations: an analysis of managerial incentives in the mutual fund industry," Journal of Finance 51(1), 85110.

Brown, Stephen and William Goetzmann, 1997, "Mutual Fund Styles.” Journal of Financial Economics 431997 373-399

Brown, Stephen J., William N. Goetzmann and Roger G. Ibbotson, 1999, "Offshore hedge funds,: survival and performance, 1989 - 1995." Journal of Business, 72(1) 91-119. .

Brown, Stephen J., William N. Goetzmann, Roger G. Ibbotson and Stephen A Ross, 1992, "Survivorship Bias in Performance Studies," Review of Financial Studies, 5, 553-580.

Brown, Stephen J., William N. Goetzmann, Roger G. Ibbotson and Stephen A Ross, 2997, "Rejoinder: The J-shape of performance persistence given survivorship bias," Review of Economics and Statistics, 79. 167-170.

Carpenter, Jennifer, 1997, "The optimal investment policy for a fund manager compensated with an incentive fee," working paper, Stern School of Management, NYU.

Carpenter, Jennifer, and Anthony Lynch 1999, "Survivorship bias and reversals in mutual fund performance," Journal of Financial Economics (forthcoming).

Carhart, Mark, 1997, "Mutual fund survivorship," working paper, University of Southern C alifornia Marshall School of Business.

Fung, William and David Hsieh, 1997, "Empirical characteristics of dynamic trading strategies: the case of hedge funds," the Review of Financial Studies, 10,2, Summer, pp. 275-302.

Fung, William and David Hsieh, 1997b, "Survivorship bias and investment style in the returns of CTAs: the information content of performance track records, " Journal of Portfolio Management, $24,30-41$.

Goetzmann, William, Jonathan Ingersoll, Jr. and Stephen A. Ross, 1997, "High water marks," Yale School of Management Working Paper.

Greene, William, 1997, Econometric Analysis (Prentice Hall, New Jersey) 
Grinblatt, Mark and Sheridan Titman, 1989, "Adverse risk Incentives and the design of performance-based contracts," Management Science, 35, 807-822.

Hendricks, Daryl, Jayendu Patel and Richard Zeckhauser, 1997, "The J-shape of performance persistence given survivorship bias," Review of Economics and Statistics, 79. 161-166.

Lunde, Asger, Allan Timmermann and David Blake, 1999 "The hazards of underperformance: A Cox regression analysis," Journal of Empirical Finance, 6. 121-152.

Massa, Massimo, 1997, "Do investors react to mutual fund performance? An imperfect competition approach?" Yale University Department of Economics Working Paper.

Park, James M., 1995, "Managed futures as an investment asset," Doctoral dissertation, Columbia University.

Brown, Stephen J., William N. Goetzmann, Roger G. Ibbotson and Stephen A. Ross,

Starks, Laura, 1987, "Performance incentive fees: an agency-theoretic approach," Journal of Financial and Quantitative Analysis, 22, 17-32. 
Table 1: Augmented TASS Database of CTAs and Funds

\begin{tabular}{|c|c|c|c|c|c|c|c|c|}
\hline & \multicolumn{4}{|c|}{ CTAs } & \multicolumn{4}{|c|}{ Hedge Funds } \\
\hline & $\begin{array}{l}\text { Total } \\
\text { Funds }\end{array}$ & $\begin{array}{l}\text { New } \\
\text { Funds }\end{array}$ & $\begin{array}{l}\text { Bankrupt } \\
\text { Funds }\end{array}$ & $\begin{array}{l}\text { Surviving } \\
\text { Funds }\end{array}$ & $\begin{array}{l}\text { Total } \\
\text { Funds }\end{array}$ & $\begin{array}{l}\text { New } \\
\text { Funds }\end{array}$ & $\begin{array}{l}\text { Bankrupt } \\
\text { Funds }\end{array}$ & $\begin{array}{l}\text { Surviving } \\
\text { Funds }\end{array}$ \\
\hline 1971 & 1 & 1 & 0 & 1 & & & & \\
\hline 1972 & 1 & 0 & 0 & 1 & & & & \\
\hline 1973 & 2 & 1 & 0 & 2 & & & & \\
\hline 1974 & 3 & 1 & 0 & 3 & & & & \\
\hline 1975 & 4 & 1 & 0 & 4 & & & & \\
\hline 1976 & 6 & 2 & 0 & 6 & & & & \\
\hline 1977 & 7 & 1 & 0 & 7 & 2 & 2 & 0 & 2 \\
\hline 1978 & 8 & 1 & 0 & 8 & 4 & 2 & 0 & 4 \\
\hline 1979 & 13 & 5 & 0 & 13 & 5 & 1 & 0 & 5 \\
\hline 1980 & 20 & 7 & 0 & 20 & 6 & 1 & 0 & 6 \\
\hline 1981 & 29 & 9 & 0 & 29 & 8 & 2 & 0 & 8 \\
\hline 1982 & 37 & 8 & 0 & 37 & 12 & 4 & 0 & 12 \\
\hline 1983 & 50 & 13 & 0 & 50 & 19 & 7 & 0 & 19 \\
\hline 1984 & 77 & 27 & 0 & 77 & 28 & 9 & 0 & 28 \\
\hline 1985 & 107 & 30 & 0 & 107 & 35 & 7 & 0 & 35 \\
\hline 1986 & 142 & 35 & 1 & 141 & 53 & 18 & 0 & 53 \\
\hline 1987 & 189 & 47 & 3 & 185 & 82 & 29 & 0 & 82 \\
\hline 1988 & 254 & 65 & 5 & 245 & 109 & 27 & 0 & 109 \\
\hline 1989 & 443 & 99 & 13 & 331 & 151 & 21 & 0 & 130 \\
\hline 1990 & 563 & 116 & 51 & 396 & 258 & 64 & 0 & 194 \\
\hline 1991 & 750 & 177 & 65 & 508 & 304 & 55 & 0 & 249 \\
\hline 1992 & 870 & 181 & 72 & 617 & 457 & 104 & 1 & 352 \\
\hline 1993 & 975 & 179 & 97 & 699 & 706 & 177 & 2 & 527 \\
\hline 1994 & 1055 & 178 & 132 & 745 & 877 & 175 & 16 & 686 \\
\hline 1995 & 1091 & 173 & 131 & 787 & 1096 & 205 & 57 & 834 \\
\hline 1996 & 1069 & 141 & 130 & 798 & 1290 & 228 & 110 & 952 \\
\hline 1997 & 1036 & 119 & 78 & 839 & 1410 & 229 & 110 & 1071 \\
\hline 1998 & 995 & 78 & 146 & 771 & 1411 & 170 & 168 & 1073 \\
\hline
\end{tabular}




\section{Survival of CTAs and Hedge Funds}

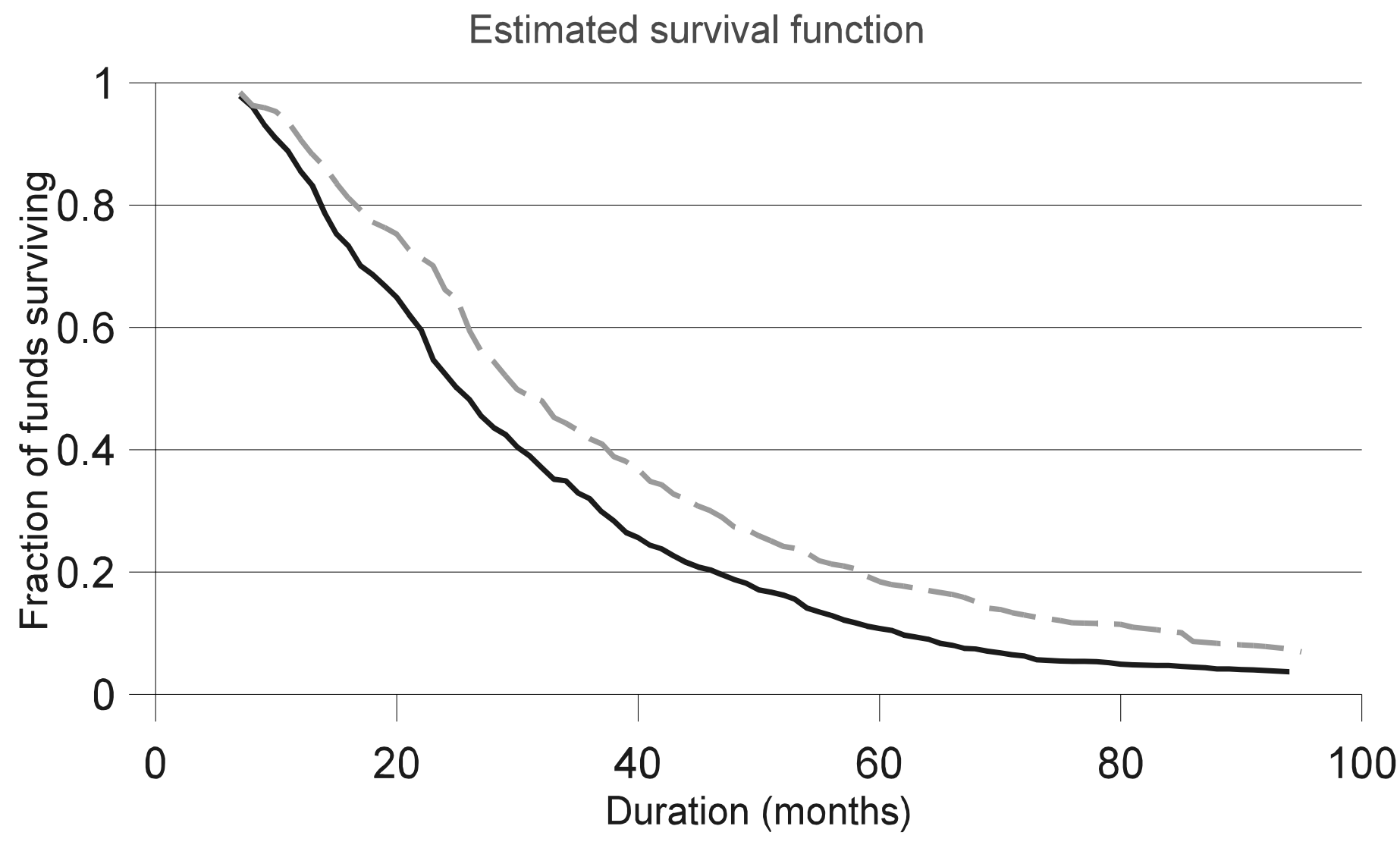

\section{CTAs}

Hedge Funds

Figure 1

This figure gives the fraction of funds alive after six months that survive in the database for the specified duration of time. This calculation excludes the CTA funds in the database prior to January 1989. We exclude hedge funds in the database prior to January 1994 on the grounds that data on the number of nonsurvivors prior to that date are nonexistent or unreliable. 


\section{CTA Returns and Volatility Change}

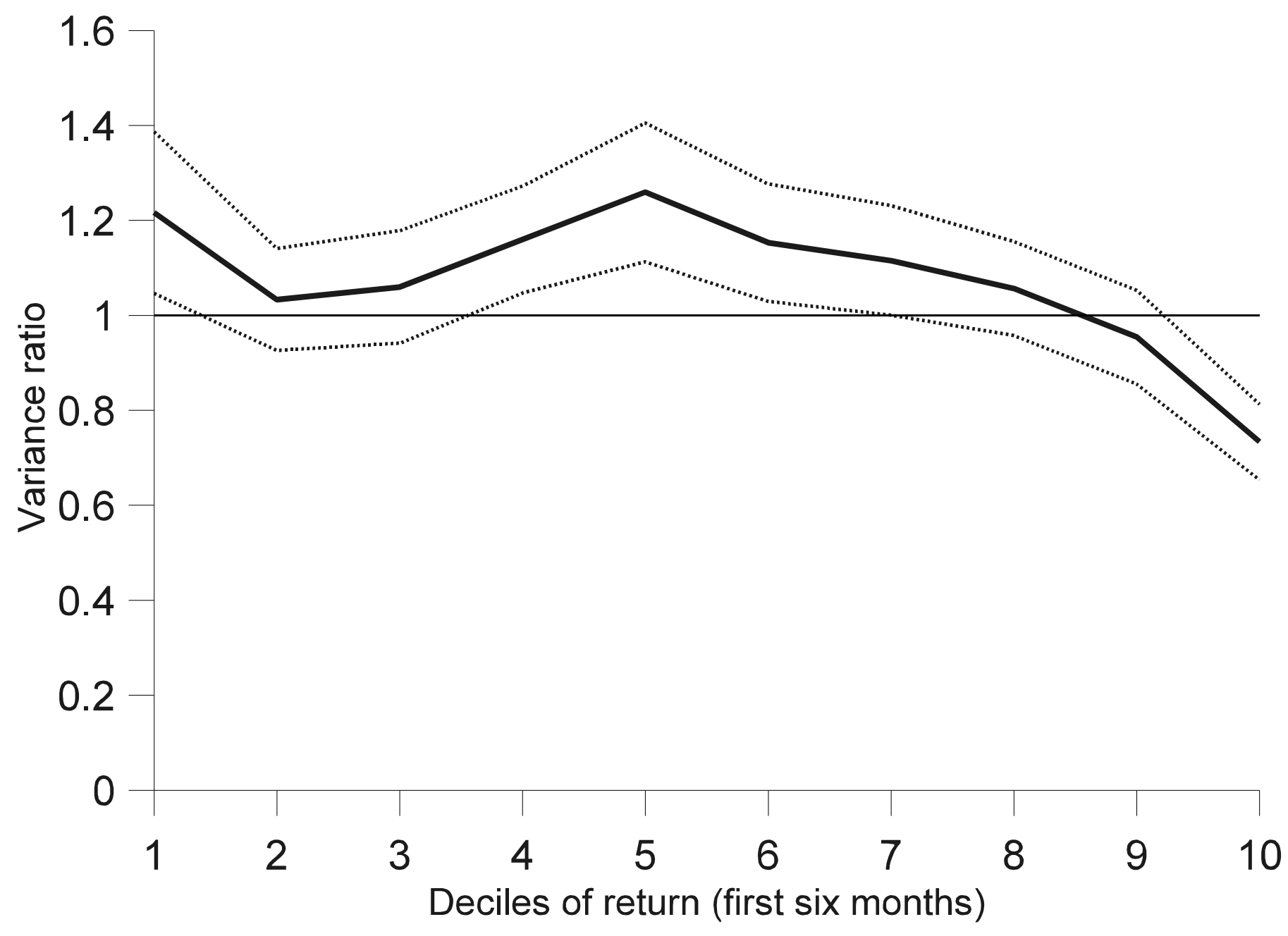

Figure 2

This figure gives the change in volatility for CTAs as a function of relative performance in the first six months. The solid line gives the median volatility ratio for all CTA funds in the sample period 1989-98 with at least one year of complete data, and the dotted lines give the $95 \%$ confidence band for the median. The variance ratio is defined as the ratio of variance of return in excess of style benchmark for the second six month period to the variance of the first six month excess return, and deciles of return are defined relative to realized return measured over the first six months, and excess return is defined relative to style benchmarks. This classification is repeated for each year of our sample 1989-98. 


\section{Hedge Fund Returns and Volatility Change}

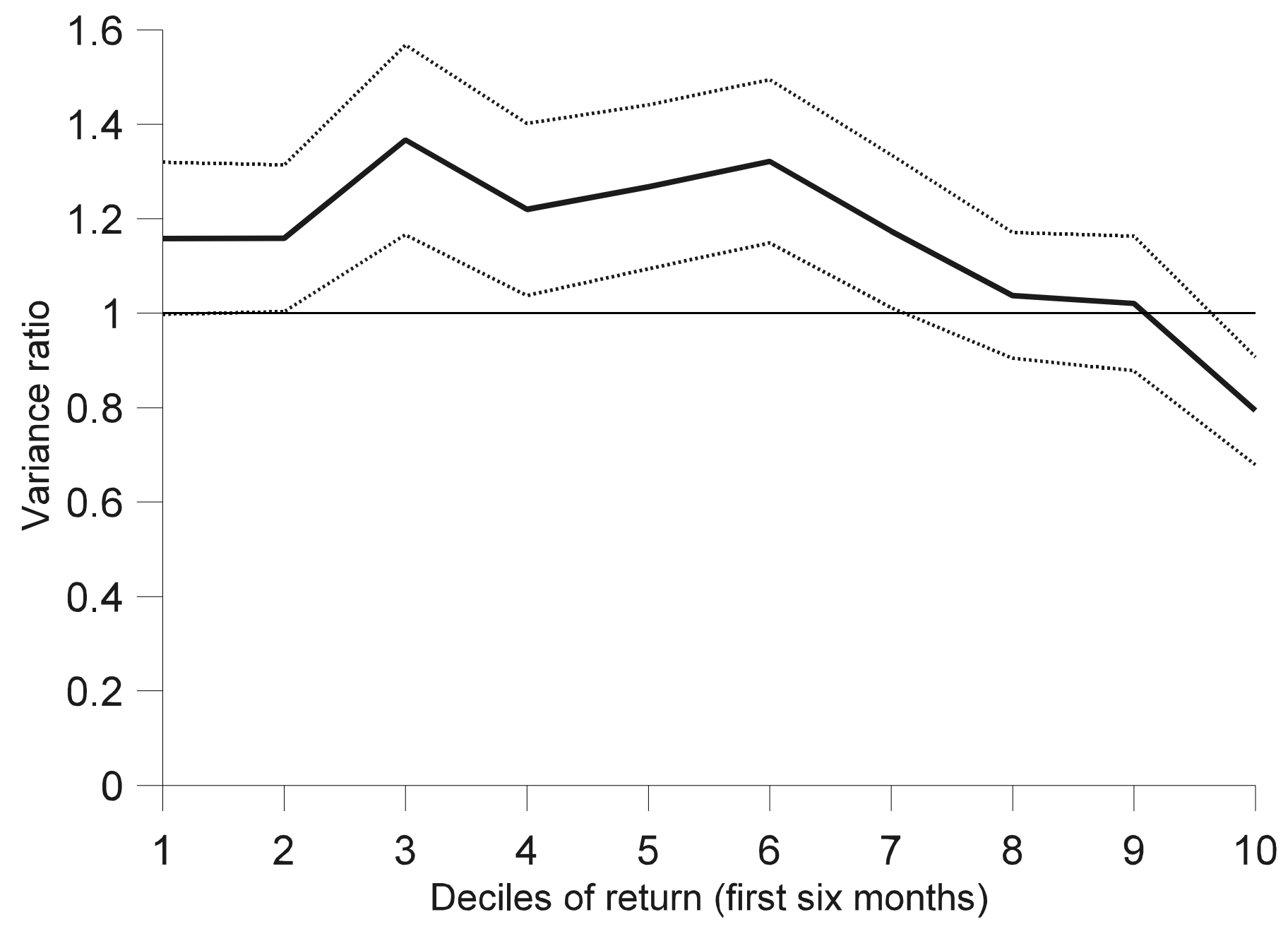

Figure 3

This figure gives the change in volatility for hedge funds as a function of relative performance in the first six months. The solid line gives the median volatility ratio for all hedge funds in the sample period 1989-98 with at least one year of complete data, and the dotted lines give the $95 \%$ confidence band for the median. The variance ratio is defined as the ratio of variance of return in excess of style benchmark for the second six month period to the variance of the first six month excess return, and deciles of return are defined relative to realized return measured over the first six months, and excess return is defined relative to style benchmarks. This classification is repeated for each year of our sample 1989-98. 


\section{Table 2: Returns and Subsequent Volatility Change (All Funds)}

\begin{tabular}{|c|c|c|c|c|c|c|c|}
\hline \multirow[b]{3}{*}{ Year } & \multicolumn{7}{|c|}{ a. Median Return Benchmark } \\
\hline & \multicolumn{2}{|c|}{$\begin{array}{l}\text { Funds with Jan-Jun return less than } \\
\text { median }\end{array}$} & \multicolumn{2}{|c|}{$\begin{array}{l}\text { Funds with Jan-Jun return greater than } \\
\text { median }\end{array}$} & \multirow{2}{*}{$\begin{array}{l}\text { Log } \\
\text { odds } \\
\text { ratio }\end{array}$} & \multirow[b]{2}{*}{ t-value } & \multirow[b]{2}{*}{$\begin{array}{l}\text { Chi- } \\
\text { square }\end{array}$} \\
\hline & Variance ratio low & Variance ratio high & Variance ratio low & Variance ratio high & & & \\
\hline 1989 & 92 & 126 & 126 & 93 & -0.6182 & -3.19 & $10.27 * *$ \\
\hline 1990 & 122 & 156 & 156 & 122 & -0.4917 & -2.88 & $8.32 * *$ \\
\hline 1991 & 149 & 180 & 180 & 149 & -0.3780 & -2.41 & $5.84^{*}$ \\
\hline 1992 & 201 & 212 & 212 & 201 & -0.1066 & -0.77 & 0.59 \\
\hline 1993 & 245 & 283 & 283 & 245 & -0.2884 & -2.34 & $5.47 *$ \\
\hline 1994 & 303 & 322 & 322 & 304 & -0.1183 & -1.05 & 1.09 \\
\hline 1995 & 357 & 363 & 363 & 358 & -0.0305 & -0.29 & 0.08 \\
\hline 1996 & 368 & 428 & 428 & 369 & -0.2994 & -2.98 & $8.89 * *$ \\
\hline 1997 & 442 & 440 & 440 & 443 & 0.0113 & 0.12 & 0.01 \\
\hline 1998 & 411 & 468 & 468 & 411 & -0.2598 & -2.72 & $7.39 * *$ \\
\hline \multirow[t]{3}{*}{ 1989-90 } & 2690 & 2978 & 2978 & 2695 & -0.2016 & -5.36 & $28.75^{* *}$ \\
\hline & \multicolumn{7}{|c|}{ b. Zero Return Benchmark } \\
\hline & \multicolumn{2}{|c|}{$\begin{array}{c}\text { Funds with Jan-Jun return less than } \\
\text { zero }\end{array}$} & \multicolumn{2}{|c|}{ Funds with Jan-Jun return greater than zero } & $\log$ & & \\
\hline Year & Variance ratio low & Variance ratio high & Variance ratio low & Variance ratio high & $\begin{array}{l}\text { odds } \\
\text { ratio }\end{array}$ & t-value & $\begin{array}{l}\text { Chi- } \\
\text { square }\end{array}$ \\
\hline 1989 & 41 & 51 & 177 & 168 & -0.2704 & -1.15 & 1.32 \\
\hline 1990 & 31 & 65 & 247 & 213 & -0.8885 & -3.74 & $14.55^{* *}$ \\
\hline 1991 & 113 & 131 & 216 & 198 & -0.2348 & -1.45 & 2.11 \\
\hline 1992 & 198 & 202 & 215 & 211 & -0.0388 & -0.28 & 0.08 \\
\hline 1993 & 68 & 74 & 460 & 454 & -0.0977 & -0.54 & 0.29 \\
\hline 1994 & 289 & 305 & 336 & 321 & -0.0996 & -0.88 & 0.77 \\
\hline 1995 & 190 & 166 & 530 & 555 & 0.1811 & 1.48 & 2.19 \\
\hline 1996 & 191 & 195 & 605 & 602 & -0.0257 & -0.22 & 0.05 \\
\hline 1997 & 198 & 163 & 684 & 720 & 0.2458 & 2.07 & $4.32 *$ \\
\hline 1998 & 311 & 315 & 568 & 564 & -0.0198 & -0.2 & 0.04 \\
\hline $1989-90$ & 1630 & 1667 & 4038 & 4006 & -0.0304 & -0.74 & 0.54 \\
\hline
\end{tabular}

Numbers in the body of the table give the number of funds falling in each classification. Each fund was required to have a complete return history for each calendar year. Jan-Jun return is defined as the total fund return measured over the first six months of each year, and is measured relative to a benchmark of the median fund return over that six month period (Median return benchmark) or zero (Zero return benchmark). The variance ratio is defined as the ratio of variance of return in excess of style benchmark for the second six month period to the variance of the first six month excess return. Variance ratio low is defined as a variance ratio less than the median for all 
funds in the calendar year, and variance ratio high is defined as a variance ratio greater than or equal to the median for all funds. Similar results were obtained defining the variance ratio in terms of realized returns as opposed to excess returns. The log-odds ratio is the log of the ratio of the product of the first and fourth columns to the product of the second and third, and the t-value measures significance of this quantity. The Chi-square numbers represent the $\chi^{2}(1)$ statistics from the $2 \times 2$ contingency tables, with values significant at the $5 \%$ level denoted by a single asterisk, and those significant at the $1 \%$ level by a double asterisk. Note that this contingency table statistic is misspecified in this application since the cell counts are not independent. The log odds ratio statistic is robust to this misspecification. 


\section{Table 3: Returns and Subsequent Volatility Change (CTAs)}

\begin{tabular}{|c|c|c|c|c|c|c|c|}
\hline \multirow[b]{3}{*}{ Year } & \multicolumn{7}{|c|}{ a. Median Return Benchmark } \\
\hline & \multicolumn{2}{|c|}{$\begin{array}{l}\text { Funds with Jan-Jun return less than } \\
\text { median }\end{array}$} & \multicolumn{2}{|c|}{$\begin{array}{l}\text { Funds with Jan-Jun return greater than } \\
\text { median }\end{array}$} & \multirow{2}{*}{$\begin{array}{l}\text { Log } \\
\text { odds } \\
\text { ratio }\end{array}$} & \multirow[b]{2}{*}{ t-value } & \multirow[b]{2}{*}{$\begin{array}{l}\text { Chi- } \\
\text { square }\end{array}$} \\
\hline & Variance ratio low & Variance ratio high & Variance ratio low & Variance ratio high & & & \\
\hline 1989 & 74 & 106 & 106 & 75 & -0.7053 & -3.30 & $11.00 * *$ \\
\hline 1990 & 95 & 126 & 126 & 95 & -0.5648 & -2.94 & $8.70 * *$ \\
\hline 1991 & 113 & 131 & 131 & 114 & -0.2868 & -1.58 & 2.51 \\
\hline 1992 & 152 & 143 & 143 & 152 & 0.1221 & 0.74 & 0.55 \\
\hline 1993 & 165 & 184 & 184 & 165 & -0.2180 & -1.44 & 2.07 \\
\hline 1994 & 173 & 197 & 197 & 174 & -0.2541 & -1.73 & 2.98 \\
\hline 1995 & 185 & 212 & 212 & 185 & -0.2725 & -1.91 & 3.67 \\
\hline 1996 & 214 & 201 & 201 & 215 & 0.1300 & 0.94 & 0.88 \\
\hline 1997 & 214 & 227 & 227 & 215 & -0.1133 & -0.84 & 0.71 \\
\hline 1998 & 195 & 222 & 223 & 196 & -0.2587 & -1.87 & 3.49 \\
\hline \multirow[t]{3}{*}{$1989-90$} & 1580 & 1749 & 1750 & 1586 & -0.2000 & -4.08 & $16.64 * *$ \\
\hline & \multicolumn{7}{|c|}{ b. Zero Return Benchmark } \\
\hline & \multicolumn{2}{|c|}{$\begin{array}{l}\text { Funds with Jan-Jun return less than } \\
\text { zero }\end{array}$} & \multicolumn{2}{|c|}{ Funds with Jan-Jun return greater than zero } & $\log$ & & \\
\hline Year & Variance ratio low & Variance ratio high & Variance ratio low & Variance ratio high & $\begin{array}{l}\text { odds } \\
\text { ratio }\end{array}$ & t-value & $\begin{array}{l}\text { Chi- } \\
\text { square }\end{array}$ \\
\hline 1989 & 39 & 50 & 141 & 131 & -0.3220 & -1.31 & 1.72 \\
\hline 1990 & 29 & 58 & 192 & 163 & -0.8569 & -3.41 & $12.04 * *$ \\
\hline 1991 & 98 & 112 & 146 & 133 & -0.2268 & -1.24 & 1.54 \\
\hline 1992 & 174 & 165 & 121 & 130 & 0.1249 & 0.75 & 0.56 \\
\hline 1993 & 62 & 60 & 287 & 289 & 0.0397 & 0.20 & 0.04 \\
\hline 1994 & 153 & 172 & 217 & 199 & -0.2036 & -1.37 & 1.89 \\
\hline 1995 & 90 & 92 & 307 & 305 & -0.0285 & -0.17 & 0.03 \\
\hline 1996 & 175 & 147 & 240 & 269 & 0.2884 & 2.02 & $4.09 *$ \\
\hline 1997 & 139 & 123 & 302 & 319 & 0.1771 & 1.20 & 1.44 \\
\hline 1998 & 207 & 234 & 211 & 184 & -0.2595 & -1.87 & 3.5 \\
\hline $1989-90$ & 1166 & 1213 & 2164 & 2122 & -0.0591 & -1.16 & 1.34 \\
\hline
\end{tabular}

Numbers in the body of the table give the number of CTAs falling in each classification. Each fund was required to have a complete return history for each calendar year. Jan-Jun return is defined as the total fund return measured over the first six months of each year, and is measured relative to a benchmark of the median fund return over that six month period (Median return benchmark) or zero (Zero return benchmark). The variance ratio is defined as the ratio of variance of return in excess of style benchmark for the second six month period to the variance of the first six month excess return. Variance ratio low is defined as a variance ratio less than the median for all 
funds in the calendar year, and variance ratio high is defined as a variance ratio greater than or equal to the median for all funds. Similar results were obtained defining the variance ratio in terms of realized returns as opposed to excess returns. The log-odds ratio is the log of the ratio of the product of the first and fourth columns to the product of the second and third, and the t-value measures significance of this quantity. The Chi-square numbers represent the $\chi^{2}(1)$ statistics from the $2 \times 2$ contingency tables, with values significant at the $5 \%$ level denoted by a single asterisk, and those significant at the $1 \%$ level by a double asterisk. Note that this contingency table statistic is misspecified in this application since the cell counts are not independent. The log odds ratio statistic is robust to this misspecification. 


\section{Table 4: Returns and Subsequent Volatility Change (Hedge Funds)}

\begin{tabular}{|c|c|c|c|c|c|c|c|}
\hline \multirow[b]{3}{*}{ Year } & \multicolumn{7}{|c|}{ a. Median Return Benchmark } \\
\hline & \multicolumn{2}{|c|}{$\begin{array}{l}\text { Funds with Jan-Jun return less than } \\
\text { median }\end{array}$} & \multicolumn{2}{|c|}{$\begin{array}{l}\text { Funds with Jan-Jun return greater than } \\
\text { median }\end{array}$} & \multirow{2}{*}{$\begin{array}{l}\text { Log } \\
\text { odds } \\
\text { ratio }\end{array}$} & \multirow[b]{2}{*}{ t-value } & \multirow[b]{2}{*}{$\begin{array}{l}\text { Chi- } \\
\text { square }\end{array}$} \\
\hline & Variance ratio low & Variance ratio high & Variance ratio low & Variance ratio high & & & \\
\hline 1989 & 19 & 19 & 19 & 19 & 0 & 0 & 0 \\
\hline 1990 & 27 & 30 & 30 & 27 & -0.2107 & -0.56 & 0.32 \\
\hline 1991 & 42 & 42 & 42 & 43 & 0.0235 & 0.08 & 0.01 \\
\hline 1992 & 52 & 66 & 66 & 52 & -0.4768 & -1.82 & 3.32 \\
\hline 1993 & 80 & 99 & 99 & 80 & -0.4262 & -2 & $4.03 *$ \\
\hline 1994 & 133 & 122 & 122 & 133 & 0.1727 & 0.97 & 0.95 \\
\hline 1995 & 165 & 158 & 158 & 166 & 0.0927 & 0.59 & 0.35 \\
\hline 1996 & 171 & 210 & 210 & 171 & -0.4109 & -2.82 & $7.98 * *$ \\
\hline 1997 & 228 & 213 & 213 & 228 & 0.1361 & 1.01 & 1.02 \\
\hline 1998 & 210 & 251 & 251 & 210 & -0.3567 & -2.7 & $7.29 * *$ \\
\hline $1989-90$ & 1127 & 1210 & 1210 & 1129 & -0.1403 & -2.4 & $5.75^{*}$ \\
\hline \multicolumn{8}{|c|}{ b. Zero Return Benchmark } \\
\hline & \multicolumn{2}{|c|}{$\begin{array}{l}\text { Funds with Jan-Jun return less than } \\
\text { zero }\end{array}$} & \multicolumn{2}{|c|}{ Funds with Jan-Jun return greater than zero } & $\log$ & & \\
\hline Year & Variance ratio low & Variance ratio high & Variance ratio low & Variance ratio high & $\begin{array}{l}\text { odds } \\
\text { ratio }\end{array}$ & t-value & $\begin{array}{l}\text { Chi- } \\
\text { square }\end{array}$ \\
\hline 1989 & 1 & 2 & 37 & 36 & -0.7205 & -0.58 & 0.35 \\
\hline 1990 & 4 & 5 & 53 & 52 & -0.2422 & -0.35 & 0.12 \\
\hline 1991 & 17 & 17 & 67 & 68 & 0.0148 & 0.04 & 0 \\
\hline 1992 & 24 & 37 & 94 & 81 & -0.5817 & -1.92 & 3.74 \\
\hline 1993 & 8 & 12 & 171 & 167 & -0.4291 & -0.91 & 0.85 \\
\hline 1994 & 138 & 131 & 117 & 124 & 0.1102 & 0.62 & 0.39 \\
\hline 1995 & 100 & 74 & 223 & 250 & 0.4154 & 2.32 & $5.42 *$ \\
\hline 1996 & 20 & 44 & 361 & 337 & -0.8573 & -3.06 & $9.83 * *$ \\
\hline 1997 & 57 & 42 & 384 & 399 & 0.3437 & 1.59 & 2.56 \\
\hline 1998 & 94 & 91 & 367 & 370 & 0.0406 & 0.25 & 0.06 \\
\hline $1989-90$ & 463 & 455 & 1874 & 1884 & 0.0228 & 0.31 & 0.1 \\
\hline
\end{tabular}

Numbers in the body of the table give the number of hedge funds falling in each classification. Each fund was required to have a complete return history for each calendar year. Jan-Jun return is defined as the total fund return measured over the first six months of each year, and is measured relative to a benchmark of the median fund return over that six month period (Median return benchmark) or zero (Zero return benchmark). The variance ratio is defined as the ratio of variance of return in excess of style benchmark for the second six month period to the variance of the first six month excess return. Variance ratio low is defined as a variance ratio less than 
the median for all funds in the calendar year, and variance ratio high is defined as a variance ratio greater than or equal to the median for all funds. Similar results were obtained defining the variance ratio in terms of realized returns as opposed to excess returns. The logodds ratio is the $\log$ of the ratio of the product of the first and fourth columns to the product of the second and third, and the t-value measures significance of this quantity. The Chi-square numbers represent the $\chi^{2}(1)$ statistics from the $2 \times 2$ contingency tables, with values significant at the $5 \%$ level denoted by a single asterisk, and those significant at the $1 \%$ level by a double asterisk. Note that this contingency table statistic is misspecified in this application since the cell counts are not independent. The log odds ratio statistic is robust to this misspecification. 
Table 5: The effect of return, risk and seasoning on fund failure

a. Probit regression results

CTA results

\begin{tabular}{|c|c|c|c|c|c|c|c|}
\hline Jnder_quarter & Under_year & Under_2year & $\begin{array}{c}\text { Alpha } \\
\text { (quarter) }\end{array}$ & $\begin{array}{l}\text { Alpha } \\
\text { (year) }\end{array}$ & Age of fund & Time & $\begin{array}{l}\text { Standarc } \\
\text { deviatior }\end{array}$ \\
\hline-0.1026 & 0.2602 & 0.3647 & -0.1071 & -0.0129 & -0.0037 & 0.0199 & 0.6001 \\
\hline$(-1.64)$ & $(3.92)$ & $(6.01)$ & $(-3.36)$ & $(-0.52)$ & $(-2.76)$ & $(1.43)$ & $(1.32)$ \\
\hline-0.0869 & 0.3813 & & -0.1037 & -0.0359 & -0.0033 & 0.0179 & 1.0181 \\
\hline$(-1.40)$ & $(6.15)$ & & $(-3.27)$ & $(-1.47)$ & $(-2.50)$ & $(1.30)$ & $(2.31)$ \\
\hline
\end{tabular}

Hedge fund results

Alpha Alpha Standard

Under_quarter Under_year Under_2year (quarter) (year) Age of fund Time deviation

\begin{tabular}{rrrrrrrr}
-0.0173 & 0.1007 & 0.2544 & -0.0360 & -0.0881 & -0.0061 & 0.1561 & 3.0000 \\
$(-0.23)$ & $(1.22)$ & $(3.15)$ & $(-1.05)$ & $(-3.69)$ & $(-3.94)$ & $(7.06)$ & $(3.84)$ \\
-0.0111 & 0.2050 & & -0.0328 & -0.0965 & -0.0058 & 0.1502 & 3.5003 \\
$(-0.15)$ & $(2.76)$ & & $(-0.96)$ & $(-4.08)$ & $(-3.77)$ & $(6.90)$ & $(4.66)$ \\
\hline
\end{tabular}

b.Cox semiparametric hazard rate regression results

\section{CTA results}

\begin{tabular}{|c|c|c|c|c|c|c|}
\hline Under_quarter & Under_year & Under_2year & $\begin{array}{l}\text { Alpha } \\
\text { (quarter) }\end{array}$ & $\begin{array}{l}\text { Alpha } \\
\text { (year) }\end{array}$ & Time & $\begin{array}{l}\text { Standard } \\
\text { deviation }\end{array}$ \\
\hline-0.2318 & 0.5553 & 0.6852 & -0.2371 & -0.0255 & 0.0361 & 1.4989 \\
\hline$(-1.70)$ & $(3.88)$ & $(5.30)$ & $(-3.42)$ & $(-0.50)$ & $(1.21)$ & (1.67) \\
\hline-0.0556 & 0.7128 & & -0.1867 & -0.1006 & 0.0367 & 1.6106 \\
\hline$(-0.49)$ & $(6.45)$ & & $(-3.18)$ & $(-2.40)$ & (1.59) & $(2.50)$ \\
\hline
\end{tabular}

Hedge fund results

\begin{tabular}{ccccccc} 
Under_quarter & Under_year & Under_2year & $\begin{array}{c}\text { Alpha } \\
\text { (quarter) }\end{array}$ & $\begin{array}{l}\text { Alpha } \\
\text { (year) }\end{array}$ & Time & $\begin{array}{c}\text { Standard } \\
\text { deviation }\end{array}$ \\
-0.0080 & 0.2084 & 0.5023 & -0.0802 & -0.1663 & 0.3213 & 5.2930 \\
$(-0.05)$ & $(1.15)$ & $(2.92)$ & $(-1.03)$ & $(-3.25)$ & $(6.40)$ & $(3.73)$ \\
0.2677 & 0.4181 & & 0.0078 & -0.2065 & 0.3414 & 4.4930 \\
$(1.85)$ & $(3.06)$ & & $(0.12)$ & $(-4.81)$ & $(8.45)$ & $(3.84)$ \\
\hline
\end{tabular}

This table examines the effect of return return, risk and and seasoning on the survival of funds applying standard Probit regression and Cox semiparametric hazard rate regression procedures on failure data for CTAs for the 
period 1989-98, and hedge funds for the period 1994-98. The coefficients in the Probit model are maximum likelihood estimates $\hat{\beta}$ for the model $y_{t} *=x_{t} \beta+u_{t}$ where $u_{t}$ is a standard Normal variate and the unobserved indicator variable $y_{t} *>0$ if the fund dies in period $\mathrm{t}$ (for a standard reference, see Greene(1997) Chapter 19) with t-values in paretheses. The coefficients in the Cox semiparametric hazard rate regression model are maximum likelihood estimates $\hat{\beta}$ (t-values in parentheses) for the model $\lambda_{\tau}=\lambda_{0 \tau} e^{x_{t} \beta}{ }_{\text {where }} \lambda_{\tau}$ is the hazard rate, the fraction of funds alive prior to $\tau$ that die at $\tau$. The coefficient $\lambda_{0 \tau}$ is referred to as the baseline hazard rate. This approach makes fewer parametric assumptions about the distribution of the data and does not specify a particular functional form for the role of seasoning in the survival of funds (Lunde, Timmermann and Blake 1999). The variables Under_quarter, Under_year and Under_2year are dummy variables which are one if the fund records a negative holding period return over the prior quarter, year and two year holding periods respectively, Alpha(quarter) and Alpha(year) refer to the ratio of the excess return over the holding period as a fraction of the standard deviation of excess return measured over the prior year multiplied by the square root of the number of months in the holding period, Age of Fund is measured in months, time is a trend term measured in years and Standard Deviation is the standard deviation of excess returns measured over the prior year. 